\title{
In Memoriam: Professor Reijiro Hirano (1928-2013)
}

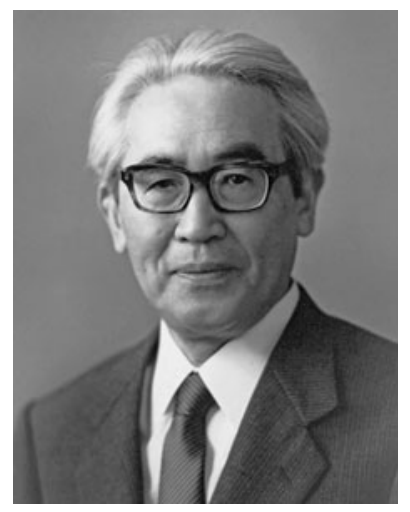

Professor Reijiro Hirano, an Honorary Member of the Japanese Society of Fisheries Science, a Professor Emeritus at the University of Tokyo, and a former Kitasato University professor, died on 1 July 2013. He was 85 years old.

Professor Hirano was born in Tokyo on 1 May 1928. He graduated from the University of Tokyo in March 1951, and was hired as an assistant professor in 1954. Since then, he held several positions within the Department of Fisheries, Faculty of Agriculture of the University of Tokyo, namely assistant professor (1954-63), associate professor (1963-74), and professor (1974-89). After reaching the mandatory retirement age of the University of Tokyo, he restarted his career with the School of Fisheries at Kitasato University and served as a professor (1989-92), the Dean (1992-94), and a board member of the Kitasato Institute (1997-2000). He was the President of the Japanese Society of Fisheries Science in 1986 and 1987.

His areas of study included the habitat study of coastal areas and resource enhancement for marine species. He established feeding techniques for the larval stages of marine species, and initiated the world's first practice of raising commercially important marine fish species including black porgy (Acanthopagrus schlegeli). He also contributed to the establishment of cryopreservation methods for the sperm of aquatic species. Another subject of his study was humus acid in the bottom sediments of coastal seas, which eventually provided the basis for wider studies of land and ocean connectivity in terms of material cycling. Ecological and physiological studies on microalgal species also constituted one of his research topics.

Although being built on basic science, many of his studies shared a common feature of contributing to practical problem solving for the fishery and aquaculture sectors. He always reminded us that "you need to study for the purpose of solving real issues faced by the society and to avoid study only for pure academic interests" and that "you need to take sides with people involved in fisheries if pressed to provide a conclusion with insufficient scientific evidence".

At the University of Tokyo, Professor Hirano actively engaged in educational activities also for foreign students. In particular, he provided opportunities for them to become involved in the most advanced research topics, which consequently allowed them to take leadership roles after returning to their home countries. He was also one of the most popular professors among students in Kitasato University, and many of whom wished to join his laboratory.

We would like to express our deepest sorrow at the passing of Professor Hirano and convey our condolences to his family. He made significant achievements in the field of fishery science and has fostered many talented individuals who are currently playing leading roles in academia, government, and business all over the world.

Hino Akinori Professor Emeritus, The University of Tokyo. 